Jurnal Geocelebes Vol. 5 No. 1, April 2021, 16 - 22

\title{
PENDUGAAN KETEBALAN LAPISAN GAMBUT DI SEKITAR JALAN REFORMASI KOTA PONTIANAK MENGGUNAKAN METODE GEOLISTRIK TAHANAN JENIS
}

\author{
Rizki Fajania, Yudha Arman, Muhardi* \\ Program Studi Geofisika, Universitas Tanjungpura, Pontianak, Indonesia \\ *Corresponding author. Email: muhardi@physics.untan.ac.id
}

Manuscript received: 15 February 2021; Received in revised form: 19 March 2021; Accepted: 25 March 2021

\begin{abstract}
Abstrak
Penelitian ini bertujuan untuk mengidentifikasi ketebalan lapisan gambut di sekitar Jalan Reformasi Kota Pontianak berdasarkan sebaran nilai tahanan jenis bawah permukaan. Pengukuran menggunakan metode geolistrik tahanan jenis dengan konfigurasi Wenner-Schlumberger. Penelitian ini mengaplikasikan empat lintasan dengan panjang masing-masing $115 \mathrm{~m}$ dan spasi antar elektroda sejauh $5 \mathrm{~m}$. Hasil penelitian menunjukkan bahwa nilai tahanan jenis yang diperoleh yaitu $0,73-1,218 \Omega \mathrm{m}$ hingga kedalaman $6-12,5 \mathrm{~m}$. Lapisan bawah permukaan di lokasi penelitian diinterpretasi sebagai gambut, lempung, dan tanah liat berpasir. Lapisan gambut diperkirakan memiliki rentang nilai tahanan jenis sebesar 18,8 - $126 \Omega \mathrm{m}$ dan merupakan lapisan paling atas yang diduga mempunyai ketebalan sebesar $3-15 \mathrm{~m}$.
\end{abstract}

Kata Kunci: gambut; Pontianak; tahanan jenis; Wenner-Schlumberger

\begin{abstract}
This study aims to identify the thickness of the peat layer around Reformasi Street, Pontianak City, based on the distribution of subsurface resistivity values. Measurements using the geoelectric resistivity method by the Wenner-Schlumberger configuration. This study applied four lines with a length of 115 $\mathrm{m}$ each and a space between the electrodes of $5 \mathrm{~m}$. The results showed that the resistivity values about $0.73-1.218 \Omega \mathrm{m}$ to a depth of $6-12.5 \mathrm{~m}$. The subsurface layers at the study area were interpreted as peat, clay, and sandy clay. The peat layer is estimated to have a resistivity value range of $18.8-126$ $\Omega \mathrm{m}$, and it is the top layer, which is guessed to have a thickness of $3-15 \mathrm{~m}$.
\end{abstract}

Keywords: peat; Pontianak; resistivity; Wenner-Schlumberger.

\section{Pendahuluan}

Kalimantan Barat merupakan provinsi terluas kedua se-Kalimantan yang memiliki total ekosistem gambut sekitar 1.729.980 Ha (Agus and Subiksa, 2008). Pada 2018, tercatat luas gambut di Provinsi Kalimantan Barat adalah 1.543.752 Ha. Pemanfaatannya di provinsi ini mengalami peningkatan setiap tahunnya walaupun belum menjangkau daerah yang luas.
Pontianak memiliki lahan gambut dengan luas 1056 Ha per tahun 2018 (BPS, 2019), hal ini karena secara geologi, Kota Pontianak umumnya merupakan endapan alluvial, pantai yang tersusun atas lumpur, pasir, kerikil, dan sisa tumbuhan (Santoyo and Pieters, 1993) seperti pada Gambar 1. Pontianak merupakan salah satu kota dengan pembangunan yang relatif pesat. Pemanfaatan lahan gambut di daerah ini berupa pengembangan wilayah perkotaan. 


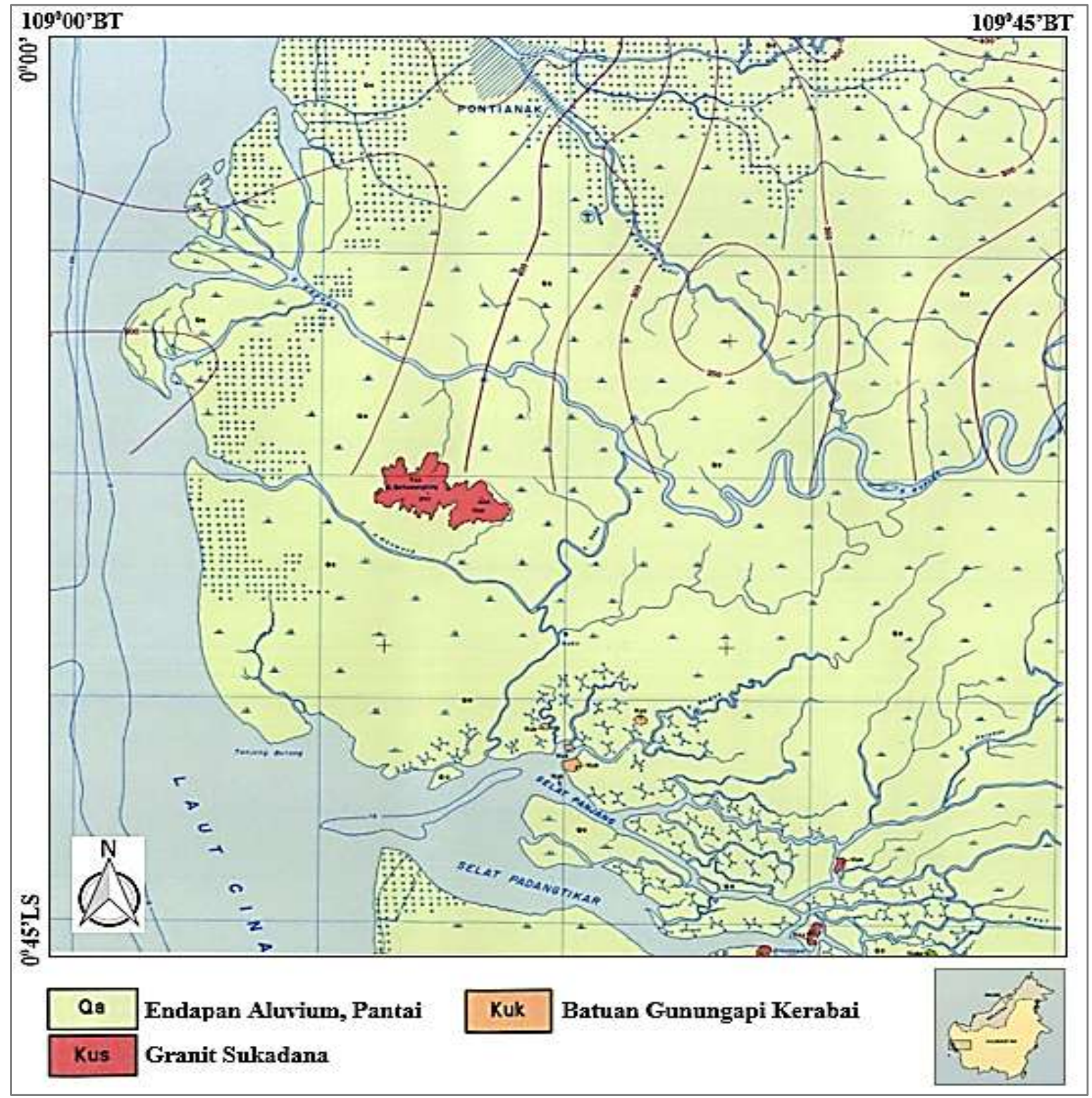

Gambar 1. Peta Geologi Kota Pontianak dan sekitarnya (dimodifikasi dari Santoyo and Pieters, 1993).

Gambut merupakan suatu lapisan yang lunak, sehingga akan beresiko apabila dibangun gedung di atasnya. Penyebabnya ialah sifat gambut yang compressible sehingga berpotensi mengalami settlement atau penurunan (Muliadi et al., 2019). Tanah gambut memiliki karakteristik yang berbeda dari lapisan lain yang berada di bawahnya. Karakteristik terkait adalah sifat kelistrikannya. Tanah gambut memiliki nilai tahanan jenis dengan nilai tertentu yang dapat dijadikan acuan dalam interpretasi, yakni sekitar 60-100 $\Omega \mathrm{m}$ (Sirait and Ihwan, 2015), 14,9-107 $\Omega \mathrm{m}$ (Ramadhaningsih and Sampurno, 2017), dan 40-709.6 $\Omega \mathrm{m}$ (Muliadi et al., 2019).
Metode geolistrik tahanan jenis dapat digunakan untuk mengidentifikasi lapisan bawah permukaan, misalnya litologi batuan (Muhardi and Wahyudi, 2019), struktur bawah permukaan (Anas et al., 2020), lapisan akuifer (Nurfalaq et al., 2018; Muhardi et al., 2019), sebaran lindi (Muhardi et al., 2020), potensi longsor (Nurfalaq and Jumardi, 2019), dan sebaran mineral (Ferial et al., 2019). Konfigurasi Wenner-Schlumberger dapat digunakan dalam penelitian ini karena memiliki sensitivitas yang baik untuk survei kedalaman (Loke, 2000). Metode ini mengamati medan potensial listrik bawah permukaan (Milsom, 2002). Tujuannya 
adalah untuk mengetahui sebaran tahanan jenis (resistivitas) bawah permukaan.

Penelitian terhadap ketebalan lapisan gambut yang berada di sekitar Jalan Reformasi, Kota Pontianak perlu dilakukan karena lokasi ini merupakan pengembangan kawasan perkotaan. Hasil penelitian ini diharapkan dapat memberikan informasi ketebalan lapisan gambut sebagai acuan dalam penentuan konstruksi bangunan yang tepat di lokasi penelitian.

\section{Metode Penelitian}

Lokasi penelitian terletak di sekitar Jalan Reformasi, Kota Pontianak, Propinsi Kalimantan Barat. Pengukuran di lapangan mengaplikasikan 4 lintasan dengan panjang masing-masing 115 meter dan spasi antar elektroda sejauh 5 meter. Desain lintasan dapat dilihat pada Gambar 2.

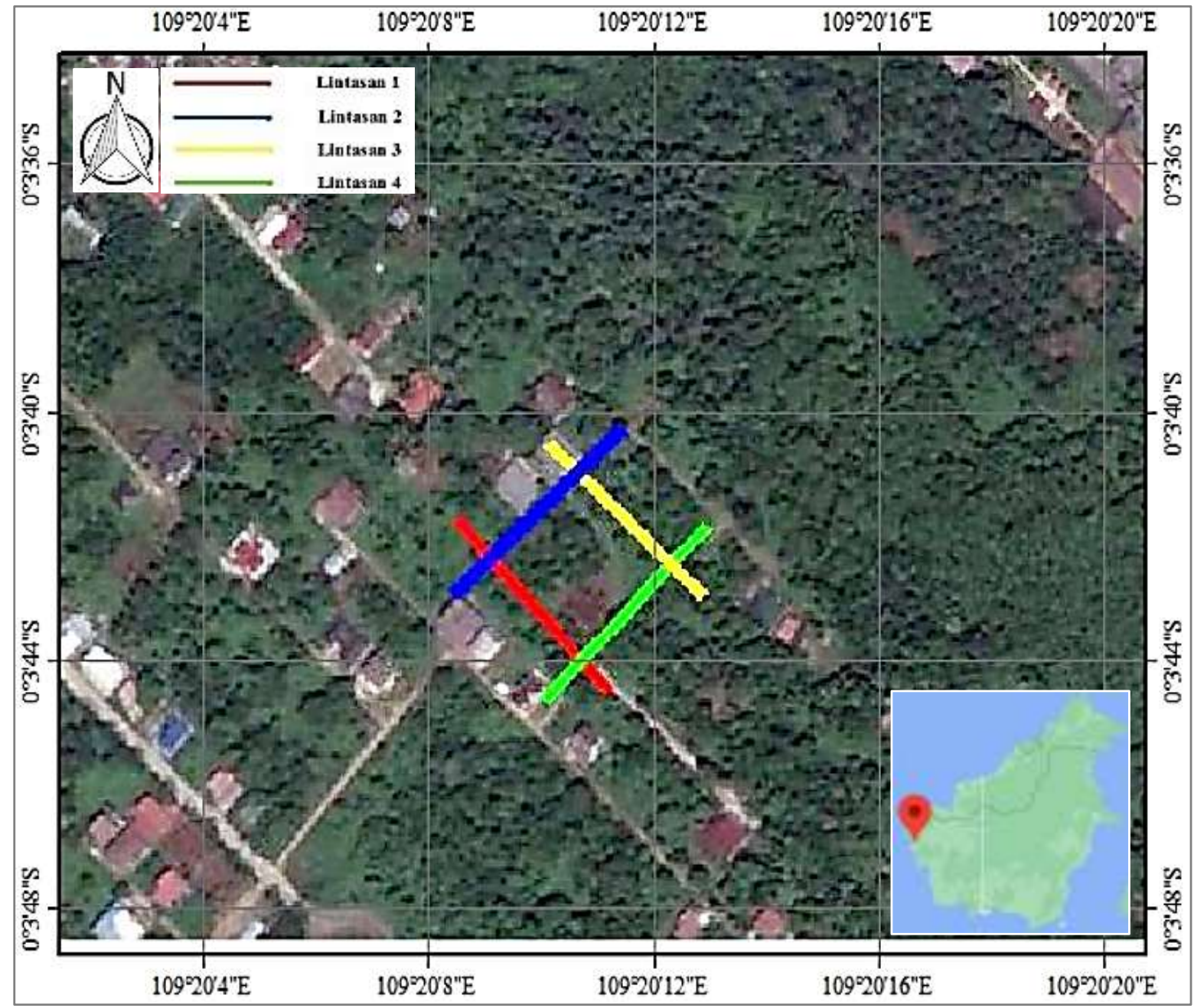

Gambar 2. Desain survei di lokasi penelitian.

Penelitian ini menggunakan konfigurasi Wenner-Schlumberger yaitu susunan elektroda dengan spasi yang konstan untuk jarak elektroda $\mathrm{P}_{1}-\mathrm{P}_{2}, \mathrm{C}_{1}-\mathrm{P}_{1}$, dan $\mathrm{P}_{2}-\mathrm{C}_{2}$, dengan faktor rasio $\mathrm{n}$. Konfigurasi WennerSchlumberger dapat dilihat pada Gambar 3.

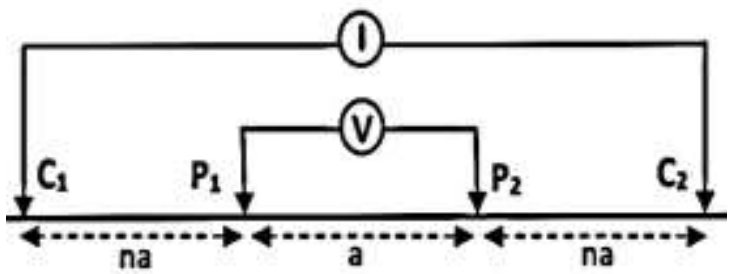

Gambar 3. Konfigurasi Wenner-Schlumberger (Loke, 2000). 
Faktor geometri $k$ ditentukan oleh susunan elektroda, untuk konfigurasi WennerSchlumberger dapat dirumuskan sebagai (Loke, 2000)

$$
k=(n+1) \pi n a
$$

Interpretasi ketebalan lapisan gambut dilakukan berdasarkan sebaran tahanan jenis yang diperoleh, kondisi geologi, dan penelitian sebelumnya di sekitar lokasi penelitian. Sebaran tahanan jenis yang sesungguhnya dihasilkan dari proses inversi tahanan jenis semu $\rho_{a}$ dan dirumuskan sebagai

$$
\rho_{a}=k\left(\frac{V}{I}\right)
$$

Setiap lapisan batuan yang dilewati aliran listrik akan menunjukkan sebaran nilai tahanan jenis yang khas baik secara vertikal maupun horizontal, karena hal ini sangat dipengaruhi oleh material penyusun batuan. Lapisan gambut yang memiliki kandungan air akan memiliki nilai tahanan jenis lebih kecil dibandingkan lapisan gambut yang tidak mengandung air. Nilai tahanan jenis gambut dan beberapa material lain dapat dilihat pada Tabel 1.

Tabel 1. Nilai tahanan jenis beberapa material (Sirait and Andi, 2015; Muliadi et al., 2019; Telford et al., 1990)

\begin{tabular}{ll}
\multicolumn{1}{c}{ Material } & \multicolumn{1}{c}{$\begin{array}{c}\text { Tahanan Jenis } \\
(\mathbf{\Omega m})\end{array}$} \\
\hline Pirit & $0,01-100$ \\
\hline Pirotit & $0,001-0,01$ \\
\hline Magnetit & $0,01-1.000$ \\
\hline Lempung & $1-100$ \\
\hline Kerikil & $100-600$ \\
\hline Pasir & $1-1000$ \\
\hline Batu Pasir & $200-8.000$ \\
\hline Gamping & $500-10.000$ \\
\hline Basal & $200-100.000$ \\
\hline Kuarsa & $500-800.000$ \\
\hline Tanah liat berpasir & $124-1107$ \\
& $14,9-107$ \\
\hline Gambut & $40-709,6$
\end{tabular}

\section{Hasil dan Pembahasan}

Hasil penelitian pada lintasan 1 hingga lintasan 4 telah mengidentifikasi lapisan gambut dengan ketebalan yang bevariasi. Selain itu, juga telah teridentifikasi lapisan lain yang berada di bawah lapisan gambut. Setiap lapisan mempunyai nilai tahanan jenis yang berbeda, dan interpretasi mengacu pada penelitian sebelumnya (Masudi et al., 2021).

Lintasan 1 berada pada koordinat 0³'52,949” LS 109²0'28,640” BT 0`3'50,425' LS $109^{\circ} 20^{\prime} 26,167^{\prime \prime}$ BT. Pada lintasan ini diperoleh nilai tahanan jenis $0,73-102 \Omega \mathrm{m}$. Ketebalan lapisan gambut pada lintasan 1 dapat dilihat pada Gambar 4. Lapisan dengan rentang nilai tahanan jenis $24,8-102 \Omega \mathrm{m}$ diinterpretasi sebagai lapisan gambut, yang memiliki ketebalan dari permukaan hingga mencapai kedalaman 6 meter. Nilai tahanan jenis 0,73 - 2,99 $\Omega \mathrm{m}$ pada kedalaman 6 - 19,8 m diinterpretasi sebagai lempung. Sedangkan nilai tahanan jenis sekitar $24,8 \Omega \mathrm{m}$ pada kedalaman 15,9 - 19,8 m yang ditunjukkan oleh warna kuning hingga coklat diinterpretasi sebagai lapisan tanah liat berpasir.

Lintasan 2 berada pada koordinat 0³'51,570" LS 109²0'26,070" BT 0³'49,129” LS 109²0'28,831" BT. Ketebalan lapisan gambut pada lintasan 2 dapat dilihat pada Gambar 5. Nilai tahanan jenis yang diperoleh pada lintasan ini memiliki rentang tahanan jenis 1,50-126 $\Omega \mathrm{m}$. Lapisan gambut diperkirakan memiliki ketebalan hingga 12,5 meter. Pada lintasan ini lapisan gambut ditunjukkan oleh warna hijau hingga ungu dengan rentang nilai tahanan jenis $18,8-$ $126 \Omega \mathrm{m}$. Nilai tahanan jenis $1,50-10 \Omega \mathrm{m}$ diinterpretasi sebagai lapisan lempung dengan mengacu pada rentang nilai tahanan jenis lempung pada Tabel 1. Sedangkan nilai tahanan jenis 35,4 $\Omega \mathrm{m}$ dengan warna kuning hingga coklat pada kedalaman 15,9 - 19,8 m diinterpretasi sebagai lapisan tanah liat berpasir. 
Depth Iteration 4 Abs. error $=16.7 \%$

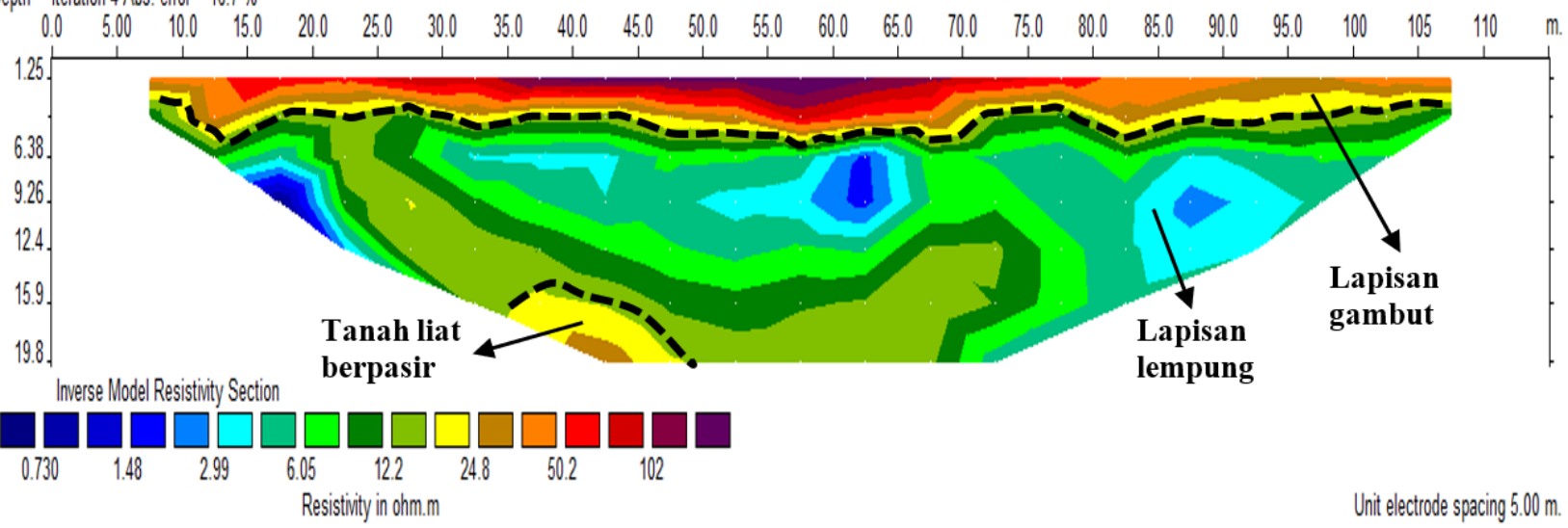

Gambar 4. Penampang 2D tahanan jenis pada lintasan 1.
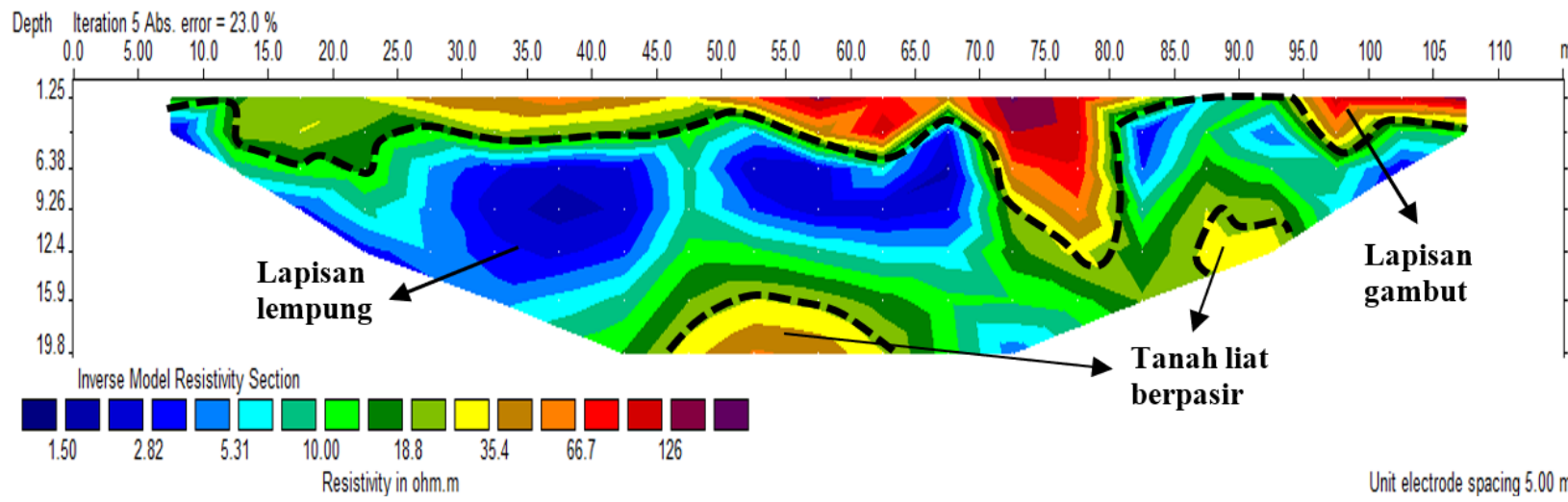

Gambar 5. Penampang 2D tahanan jenis pada lintasan 2.

Unit electrode spacing $5.00 \mathrm{~m}$.

Lintasan 3 berada pada koordinat 0³'49,298', LS 109²0'27,658' BT $0^{\circ} 3$ '51,563” LS $109^{\circ} 20^{\prime} 30,145^{\prime \prime} \quad$ BT. Ketebalan lapisan gambut pada lintasan 2 dapat dilihat pada Gambar 6. Nilai tahanan jenis yang diperoleh 4,94 - $253 \Omega \mathrm{m}$. Lapisan gambut berada di permukaan dan mencapai kedalaman hingga $6 \mathrm{~m}$. Lapisan gambut diperkirakan berada pada rentang nilai tahanan jenis $23,8-115 \Omega \mathrm{m}$ yang ditunjukkan oleh warna biru hingga hijau. Nilai tahanan jenis 4,94 - 10,9 $\Omega \mathrm{m}$ diinterpretasi sebagai lapisan lempung, yang berada pada kedalaman 1,5 - 12,4 m. Sedangkan nilai tahanan jenis sekitar 253 $\Omega \mathrm{m}$ merupakan tanah liat berpasir yang berada hingga kedalaman 19,8 m.

Depth Iteration 4 Abs. error $=39.0 \%$

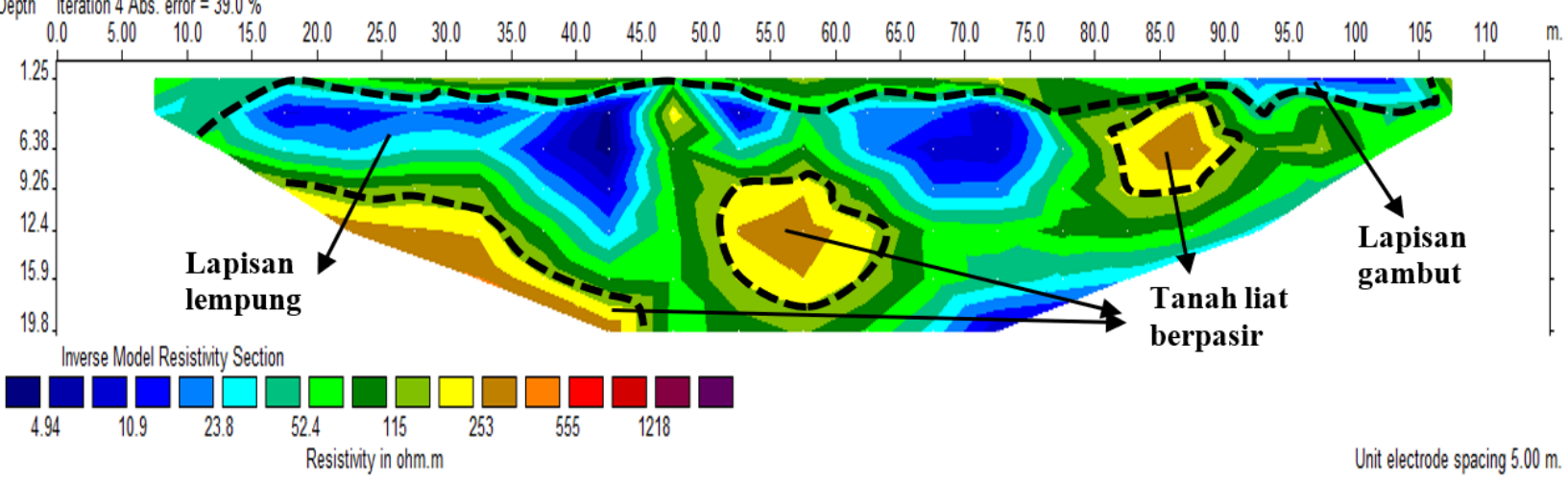

Gambar 6. Penampang 2D tahanan jenis pada lintasan 3. 


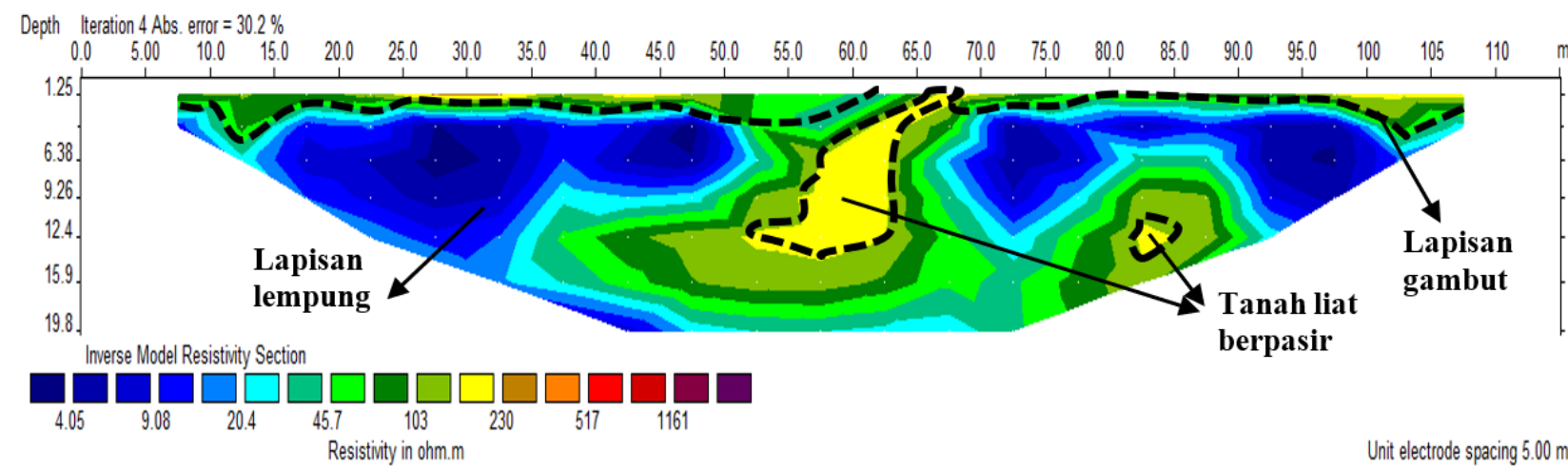

Gambar 7. Penampang 2D tahanan jenis pada lintasan .

Lintasan 4 berada pada koordinat 0³'53,100” LS 109²0'7,571" BT 0`3'50,551” LS $109^{\circ} 30,181$ ” BT. Ketebalan lapisan gambut pada lintasan 2 dapat dilihat pada Gambar 7. Nilai tahanan jenis yang diperoleh adalah 4,05-230 $\Omega \mathrm{m}$. Lapisan gambut diperkirakan berada pada rentang nilai tahanan jenis $20,4-103 \Omega \mathrm{m}$ dengan warna biru hingga hijau. Lapisan gambut berada di permukaan dan mencapai kedalaman hingga $6,3 \mathrm{~m}$. Nilai tahanan jenis 4,05 - 20,4 $\Omega \mathrm{m}$ diinterpretasi sebagai lapisan lempung yang berada pada kedalaman 1,5 - 19,8 m. Sedangkan nilai tahanan jenis sekitar $253 \Omega \mathrm{m}$ merupakan tanah liat berpasir yang berada pada kedalaman hingga $13 \mathrm{~m}$.

Lapisan gambut di lokasi penelitian umumnya mempunyai nilai tahanan jenis lebih besar jika dibandingkan dengan lapisan lempung yang tepat berada di bawahnya (Masudi et al., 2021). Hal ini diduga disebabkan karena porositas lapisan gambut yang relatif lebih besar (Muliadi et al., 2019). Kedalaman lapisan gambut mulai dari sedang $(100-200 \mathrm{~cm})$ hingga sangat dalam (lebih dari $300 \mathrm{~cm}$ ). Lapisan lempung memiliki nilai tahanan jenis yang relatif lebih kecil karena ion mineral lempung dan adanya polarisasi membran (Kurniawan, 2014). Lapisan yang lain adalah tanah liat berpasir yang dapat meloloskan fluida karena bersifat permeabel, dan interpretasi nilai tahanan jenisnya mengacu pada penelitian sebelumnya di sekitar lokasi penelitian (Ramadhaningsih and Sampurno, 2017).

\section{Kesimpulan}

Dari hasil penelitian dapat disimpulkan bahwa nilai tahanan jenis yang diperoleh yaitu $0,73-1,218 \Omega \mathrm{m}$ hingga kedalaman 6 - 12,5 m. Lapisan bawah permukaan di lokasi penelitian diinterpretasi sebagai gambut, lempung, dan tanah liat berpasir. Lapisan gambut diperkirakan memiliki rentang nilai tahanan jenis sebesar 18,8$126 \Omega \mathrm{m}$ dan merupakan lapisan paling atas yang diduga mempunyai ketebalan sebesar $3-15 \mathrm{~m}$.

\section{Daftar Pustaka}

Agus, F. and Subiksa, I. M. 2008. Lahan Gambut: Potensi untuk Pertanian dan Aspek Lingkungan. Bogor, Indonesia: Balai Penelitian Tanah dan World Agroforestry Center (ICRAF).

Anas, N. A., Syamsuddin, Harimei, B. and Nasri, M. 2020. Identifikasi Struktur Bawah Permukaan di Sekitar Manifestasi Panas Bumi Reatoa Kabupaten Maros Menggunakan Survey Geolistrik Resistivitas. Jurnal Geocelebes, 4(1):23-32.

BPS. 2019. Propinsi Kalimantan Barat dalam Angka. Pontianak: Badan Pusat Statistik Kalimantan Barat.

Ferial, D., Natalisanto, A. I. and Lazar, P. A. 2019. Identifikasi Sebaran Mineral Bijih Besi dengan Menggunakan Metode Resistivitas dan Induced (IP) di Kecamatan Muara Uya, Kabupaten Tabalong, 
Provinsi Kalimantan Selatan. Jurnal Geosains Kutai Basin, 2(2):1-9.

Kurniawan, A. 2014 Sifat Resistivitas Rendah Mineral Lempung. Masyarakat Ilmu Bumi Indonesia, 1(2):1-9.

Loke, D. M. 2000. Electrical Imaging Surveys for Environmental and Engineering Studies. Geoelectrical.com.

Masudi, Nurhasanah and Muhardi. 2021. Identifikasi Kedalaman Lapisan Tanah Keras Menggunakan Metode Geolistrik Tahanan Jenis (Studi Kasus: Jalan Perdana Kota Pontianak). Jurnal Ilmu dan Inovasi Fisika, 5(1):59-64.

Milsom, J. 2002. Field Geophysics. Third Edit. England: Wiley.

Muhardi, Muliadi and Zulfian. 2020. Model $3 D$ Sebaran Lindi pada Lapisan Tanah di Area TPA Batulayang Pontianak Kalimantan Barat Berdasarkan Nilai Resistivitas. Jurnal Fisika Flux, 17(2):73-79.

Muhardi, Perdhana, R. and Nasharuddin. 2019. Identifikasi Keberadaan Air Tanah Menggunakan Metode Geolistrik Resistivitas Konfigurasi Schlumberger (Studi Kasus: Desa Clapar Kabupaten Banjarnegara. Prisma Fisika, 7(3):331-336.

Muhardi and Wahyudi. 2019. Identifikasi Litologi Area Rawan Longsor di Desa Clapar-Banjarnegara Menggunakan Metode Geolistrik Resistivitas Konfigurasi Schlumberger. Jurnal Fisika, 9(2):52-59.

Muliadi, Zulfian and Muhardi. 2019. Identifikasi Ketebalan Tanah Gambut Berdasarkan Nilai Resistivitas 3D: Studi Kasus Daerah Tempat Pembuangan Akhir Batu Layang Kota Pontianak. Positron, 9(2):86-94.

Nurfalaq, A., Nawir, A., Manrulu, R. H. and Umar, E. P. 2018. Identifikasi Akuifer Daerah Pallantikang Kabupaten Jeneponto dengan
Metode Geolistrik. Jurnal Fisika Flux, 15(2):117-127.

Nurfalaq, A. and Jumardi, A. 2019. Identifikasi Batuan Bawah Permukaan Daerah Longsor Kelurahan Kambo Kota Palopo Menggunakan Metode Geolistrik Konfigurasi Dipole-Dipole. Jurnal Geocelebes, 3(2): 66-74.

Ramadhaningsih, L. and Sampurno, J. 2017. Identifikasi Struktur Lapisan Bawah Permukaan Lahan Gambut di Desa Arang Limbung Kecamatan Sungai Raya Kabupaten Kubu Raya dengan Metode Resistivitas Konfigurasi Dipole-Dipole. Physics Communication, 1(2): 29-35.

Santoyo, P. and Pieters, P. E. 1993. Peta Geologi

Lembar Pontianak/Nangataman,

Kalimantan. Bandung: Badan Penelitisn dan Pengembangan Geologi.

Sirait, F. and Ihwan, A. 2015. Identifikasi struktur lapisan tanah gambut sebagai informasi awal rancang bangunan dengan metode geolistrik. Prisma Fisika, 3(2):8-12.

Telford, W. M., Geldart, L. P. and Sheriff, R. E. 1990. Applied Geophysics. Second Edition. New York: Cambridge University Press. 